\title{
Effects of wave exposure on the sublittoral distribution of blue mussels Mytilus edulis in a heterogeneous archipelago
}

\author{
Mats Westerbom ${ }^{1,2,3, *}$, Sofia Jattu ${ }^{2,3}$ \\ ${ }^{1}$ Aronia Research Centre, Åbo Akademi University and Sydväst Polytechnic, Raseborgsvägen 9, 10600 Ekenäs, Finland \\ ${ }^{2}$ Department of Biological and Environmental Sciences, Division of Ecology and Evolutionary Biology, PB 65, \\ 00014 University of Helsinki, Finland \\ ${ }^{3}$ Tvärminne Zoological Station, J. A. Palménintie 260, 10900 Hanko, Finland
}

\begin{abstract}
Exposure to wave action is an important factor determining the distribution and abundance of marine species on rocky shores. We studied the primary and secondary effects of wave exposure on sublittoral blue mussel Mytilus edulis populations in a fragmented archipelago in the tideless northeastern Baltic Sea. Triplicate bottom samples were collected by SCUBA divers from 4 depths at 30 locations along a wave exposure gradient defined by an exposure index. From 15 of these locations, water samples were collected in order to measure physicochemical and biological conditions at each site. Results showed that mussel densities increased steadily with increasing wave exposure. Biomasses, however, were highest at areas with intermediate exposure. Water chemistry, seston and chlorophyll a concentrations did not differ between locations. Recruitment and growth experiments on artificial substrata carried out at the same 30 locations showed that exposure neither influenced the abundance of recruits on ropes nor markedly influenced the growth of adult mussels. This suggests that lack of mussels at less exposed localities may originate from problems in recruitment processes to adult populations or early post-recruitment mortality. We hypothesize that even thin films of stagnant sediment on rocks may have a profoundly negative effect on mussel recruitment. Results suggest that increasing sedimentation of rocky bottoms may limit the spatial distribution of mussels, pushing stable mussel beds towards outermost areas of the archipelago where strong wave action keeps bottoms free of sediments.
\end{abstract}

KEY WORDS: Physical stress $\cdot$ Predation $\cdot$ Recruitment $\cdot$ Rocky shore $\cdot$ Sedimentation $\cdot$ Artificial substrata $\cdot$ Wave exposure index $\cdot$ Depth distribution

\section{INTRODUCTION}

Patterns of species distribution in marine coastal areas have long intrigued ecologists, and understanding the processes affecting these patterns has been of central interest in rocky shore ecology. A variety of physical and biological processes, heterogeneous in time and space, have been shown to cause distinct distribution patterns.

For sessile marine species, wave action has a paramount role on almost every aspect of their ecology. Moving water influences fertilization (Pearson \& Braw- ley 1996), delivery and settlement success of larvae (Hunt \& Scheibling 1996), growth (McQuaid \& Lindsay 2000) and morphology (Stewart \& Carpenter 2003). Large waves also dislodge sessile organisms living on exposed rocky shores, leading to altered size distributions, redistribution of individuals or increased mortality (Alvarado \& Castilla 1996, McQuaid \& Lindsay 2000, Hunt \& Scheibling 2001). Wave exposure may affect the distribution and abundance of individual species, species interactions and entire rocky shore communities (McQuaid \& Branch 1985, Menge \& Branch 2001, Hammond \& Griffiths 2004). Sessile 
marine species face trade-offs between increased risks of dislodgement (and subsequent mortality) and increased nutrient supply and elevated larval dispersal along exposure gradients (Steffani \& Branch 2003).

Water motion also indirectly affects the spatial distribution of rocky shore species. Rates of siltation are often linked to water depth and movement; wave-protected sites may be subject to high levels of sediment deposition, with strong effects on sublittoral species that occupy hard substrates (Santos 1993, Kiirikki 1996, Eriksson \& Bergström 2005).

Substantial effort has been made to understand the importance of wave action in structuring intertidal mussel beds (see references in Menge \& Branch 2001). Studies of this ecotone have provided much of our understanding of the effects of wave impact on the vertical distribution of organisms on rocky shores. However, considerably less is known about the effects of wave impact on rocky subtidal communities (Witman \& Dayton 2001). The Baltic Sea in particular has not been well studied in this respect. The special conditions prevailing in the northern Baltic - the low ambient salinity, the lack of tides and the shortage of major invertebrate predators on blue mussels - put the blue mussel beds in this region in an ecologically special position. The lack of invertebrate predators is particularly important, since wave exposure and predation effects are often inversely related (Robles et al. 2001). In these circumstances, it may be difficult to isolate the separate effects of predation and wave exposure.

To better understand the influence of wave exposure on Baltic blue mussels we quantified both resident adult populations and the potential pool of recruits along an exposure gradient. (1) We determined the concentrations of food available for mussels in ambient seawater. The role of variation in primary productivity and ambient food concentrations in explaining the structure of rocky shore communities has been largely overlooked (Bustamante et al. 1995) but its potential influence on abundance and size structure of populations has been highlighted in recent years (Bustamante \& Branch 1996, Gardner 2000, Menge \& Branch 2001, Morgan 2001). (2) We investigated the strength of the relationship between abundance of sublittoral Baltic blue mussels and exposure regimes. Few studies on marine invertebrates have used numerical methods to demonstrate a tight link between exposure regimes and invertebrate abundance. The relevant physical mechanisms that influence benthic organisms are not fully known and, therefore, precise measurement of wave exposure has proven difficult (Denny 1995). Consequently, wave exposure has typically been determined subjectively (high, intermediate and low, or only exposed and sheltered) and rarely quantified (Denny 1995, Ham- mond \& Griffiths 2004). (3) We studied the effect of wave exposure on mussel growth along the gradient. Wave exposure has been shown to either increase or decrease mussel growth (McQuaid et al. 2000, Vuorinen et al. 2002) but the effects of wave exposure have not been studied experimentally in the Baltic. (4) We determined the availability of potential recruits at different localities and tried to determine if this could explain adult abundance. Although there is extensive literature on exposure effects on adult numbers, considerably less is known about exposure effects on recruits and settling juveniles and even less is known about how the numbers of these early life stages vary in coastal areas (Morgan 2001). This is interesting since distribution and abundance of sessile organisms, such as blue mussels, is to a large extent governed by their mobile larvae, dispersal being the premier demographic process of species with bipartite life stages. At large and intermediate spatial scales, passive dispersal is driven by hydrodynamic regimes, whereas the final small-scale distribution often depends on biological interactions (Lawrie \& McQuaid 2001, Erlandsson \& McQuaid 2004). These biological interactions take place within larger physical boundaries and depend on the framework established by physical processes.

\section{MATERIALS AND METHODS}

Study area. The study area is characterised by a mosaic of islands, islets, skerries and rocks. Exposure regimes vary greatly over short distances in this topographically complex environment (Fig. 1). Blue mussel populations in the area have shown extreme temporal variability in abundance over short periods (2 to $3 \mathrm{yr}$ ) (Westerbom et al. 2002). At the time of this study, abundances and especially biomasses were close to the maximum recorded during $10 \mathrm{yr}$ of study (M. Westerbom, O. Mustonen, M. Kilpi \& J. T. Lehtonen unpubl.). It is notable that the taxonomy of blue mussels Mytilus (spp.) is under debate. In this paper, we follow the nomenclature used in Öst \& Kilpi $(1997,1998)$, Littorin \& Gilek (1999a,b) and Vuorinen et al. (2002), and we call the mussel Mytilus edulis.

Exposure measurements. Estimations of wave exposure were made according to the Baardseth index (Baardseth 1970). Wave exposure values for the 30 localities were calculated by means of a transparent circular disc divided into 40 sectors of $9^{\circ}$. The centre of the circular disc, with a radius corresponding to $7.5 \mathrm{~km}$, was placed on a nautical sea chart (1:50 000) at the exact study site. The amount of open sea around a sampling site was chosen as a measure of exposure, and the numbers of sectors not including 


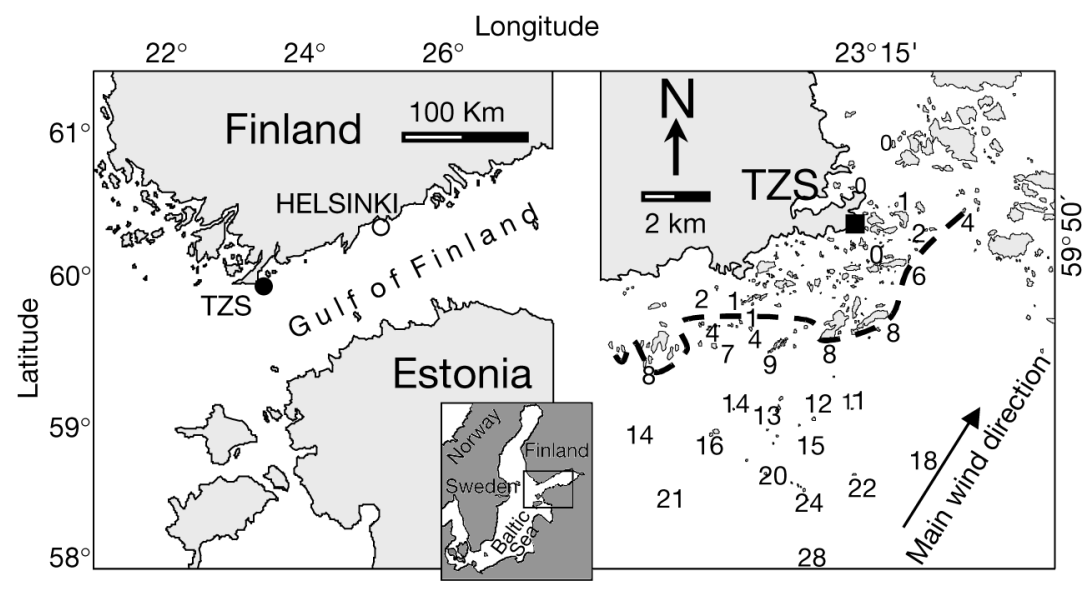

Fig. 1. The study area with sampling locations and Baardseth values (wave exposure). The dashed line indicates the border between the open pelagic zone and the outer archipelago zone. TZS: Tvärminne Zoological Station randomly from each screen were measured with vernier callipers $(0.1 \mathrm{~mm}$ accuracy), and the biomasses were estimated based on the biomass formula given in Westerbom et al. (2002). The smallest sieve collected mussels of 2 to $3 \mathrm{~mm}$ in length. Mussels smaller than $2 \mathrm{~mm}$ were therefore not recorded in this study.

Water characteristics. Fifteen sites from the overall 30, scattered over the area, were sampled on 14 occasions from June to early October at approximately 3 wk intervals in 2002 and 2003. This period corresponds largely to the productive season when sea temperature exceeds $10^{\circ} \mathrm{C}$. Samples were collected with a 2.1 l Limnos parts of the mainland, islands, islets, skerries or rocks were counted. Small solitary rocks at the periphery of the disc were ignored. The exposure index is the sum of the free sectors, where a value of 0 indicates absolute shelter and a value of 40 indicates maximal exposure. Exposed shores in the Baltic Sea would probably be regarded as sheltered shores along oceanic coasts. At the level of the study organism, the differences may be less radical since the attachment strength of Baltic blue mussels has been shown to be considerable weaker than that of their marine conspecifics (Reimer \& Harms-Ringdahl 2001). Cartographic methods of quantifying wave exposure are suitable for estimating relative wave action in fragmented and scattered archipelago (or lake) areas, estuaries and bays but less predictable in open oceanic environments where waves are generated by winds carried over hundreds or thousands of kilometres (e.g. Ruuskanen \& Nappu 2005). We also used a GIS-based wave exposure model by Isaeus (2004). The model of Isaeus uses the WaveImpact 1.0 software, a maximum fetch of $500 \mathrm{~km}$ and the main wind direction in calculating exposure values for a shore (for further details, see Isaeus 2004). Here, the main wind direction was chosen as SW (Fig. 1).

Sample collection. In late summer 2002, mussel samples were collected (SCUBA) at the most exposed sites at each locality by placing a $20 \times 20 \mathrm{~cm}$ quadrat on the bottom and removing all material within the frame into a bag. All samples were taken from gently sloping bottoms. Triplicate samples from 3, 5, 8 and $12 \mathrm{~m}$ depth, with distance between samples of approximately $10 \mathrm{~m}$, were haphazardly collected. In the laboratory, the samples were sieved through multi-mesh soil screens (mesh size: 9.5, 4, 2 and $1 \mathrm{~mm}$ ) and mussels in each mesh screen were counted. From each locality and each depth, approximately 100 mussels taken sampler from $7.5 \mathrm{~m}$ depth (mean depth of bottom samples), approximately $1 \mathrm{~m}$ above the bottom (measured with a sonar), and used to measure temperature, salinity and dissolved oxygen. Secchi depth was also recorded. The amount of food potentially available for mussels was determined by analysing chlorophyll a (hereafter chl a) and seston concentrations in the laboratory.

Seston characteristics. During each round of water sampling, 500 to $1000 \mathrm{ml}$ of seawater was filtered under gentle vacuum through pre-ignited and preweighted Whatman GF/F filters. Seston total particulate matter (TPM), particulate organic matter (POM) and particulate inorganic matter (PIM) were measured for each sample to an accuracy of $0.01 \mathrm{mg}$. TPM was determined after drying filters at $60^{\circ} \mathrm{C}(48 \mathrm{~h}), \mathrm{PIM}$ after ignition (AFDW) at $500^{\circ} \mathrm{C}(5 \mathrm{~h})$ and POM by the difference between TPM and PIM.

Chlorophyll a measurements. Phytoplankton abundance is usually indexed by chl a concentrations (e.g. Dahlhoff \& Menge 1996). Three replicate water samples of 500 to $1000 \mathrm{ml}$ were collected at each of the 15 locations. In the laboratory, water samples were immediately filtered through Whatman GF/F glass-fibre filters and chl a concentrations determined using the ethanol-extraction method and a Shimadzu spectrophotometer. Chl a concentrations were measured at 665 (maximum absorbance of chl a) and $750 \mathrm{~nm}$ (maximum absorbance of ethanol) and expressed as mg chl a $\mathrm{m}^{-3}$. In analyses, we used the mean chl a values per location per sampling date.

Recruitment and growth experiments. Artificial substrates, homogenous in surface area and textual composition, have been used to survey settlement and recruitment success of marine invertebrates (Rule \& Smith 2005) and have in some cases been shown to reliably reflect larval supply (Martel et al. 
1994). Here, recruitment of mussel larvae was surveyed using spat collectors consisting of roughed (by means of a rotating electric grinding machine) polyester ropes ( $8 \mathrm{~mm}$ in diameter) attached to bricks. Three holes were drilled (at the edge and in the centre of the brick) through the bricks and 3 lengths of rope were inserted through the holes, fixed in position and cut to $11 \mathrm{~cm}$. In late May 2003 and 2004 (well before the settlement of mussels), 5 spat collectors were randomly positioned by SCUBA-divers at $8 \mathrm{~m}$ depth, with a distance of approximately $10 \mathrm{~m}$ between the bricks, at each of the 30 localities. In late August (2003) and mid September (2004), the collectors were retrieved; $10 \mathrm{~cm}$ of each rope was cut and dried at $60^{\circ} \mathrm{C}$ for $5 \mathrm{~d}$. In the laboratory, mussels were removed by softly brushing the dry ropes. Finally, stereomicroscopes were used to ensure that no mussels were left on the ropes. Since the number of mussels per brick was extremely high in 2004, only half of the mussels were counted. Mussels were distributed evenly on a tray sectioned into 16 evenlysized sectors of which 8 were counted (every second one), the starting sector being randomly selected. We define all mussels on the ropes as recruits, although some of them may have been settlers (Hunt \& Scheibling 1997). Mussels can retain their dispersing ability up to a size of 2 to $2.5 \mathrm{~mm}$ (Seed \& Suchanek 1992), and separating actual recruits from post-larval settlers is not always clear cut. The recruitment process often encompasses high mortality of juveniles, and recruits are often defined as those individuals that have survived high (pre and post) settlementassociated mortality (Erlandsson \& McQuaid 2004). In the study area, pelagic mussel larvae are found in mid June to mid July and occur in 1 annual peak period only (Viitasalo et al. 1995, unpubl. monitoring data of the Finnish Institute of Marine Research). The study design differed between 2003 and 2004. Interannual comparisons must therefore be treated with caution.

To study the growth of mussels in 2003, plastic cages (mesh size $0.5 \mathrm{~cm}$, diameter $10 \mathrm{~cm}$ ) containing 20 mussels of mean size $14.2 \mathrm{~mm} \pm 0.02$ (SE) were attached to the bricks containing the spat collectors $(n=150)$. After retrieval of bricks in late August, all mussels were remeasured (accuracy $0.1 \mathrm{~mm}$ ) and the number of dead mussels was recorded.

Data analysis. We used parametric tests whenever possible. In some cases, noted in the text, variables were $\log +1$ or square root transformed to meet assumptions of a normal distribution or homogeneous variance (Levenes' test). Values are reported as means \pm SE unless otherwise stated. All statistical analyses were performed using the SPSS (11 for Windows) statistical package.

\section{RESULTS}

\section{Ambient water characteristics along the exposure gradient}

All sites were remarkably similar with regard to water characteristics (MANOVA $F_{\text {Wilks' Lambda }}=1.022$, $\mathrm{p}=0.422$ ) and no measured parameter showed any locality-dependent difference (Table 1 ). Water temperature ranged from $6.5^{\circ} \mathrm{C}$ in June to $23.5^{\circ} \mathrm{C}$ in mid August and thereafter temperatures gradually declined towards the autumn. Salinity varied between 5.59 and $6.65 \%$ with peak values at all sites in September (2002) and October (2003). Oxygen levels were always high, with the lowest recording being $6.5 \mathrm{mg} \mathrm{l}^{-1}$ in mid August 2002. Nutritional (seston and chl a) conditions for mussels did not differ among locations. Chl a concentrations were highest between mid July and mid August in 2003, while the peak period in 2002 occurred between mid August and mid September.

\section{Exposure effects on abundance and size structure of blue mussels}

Regression analyses between total mussel abundance and the Baardseth index showed that increasing exposure had a highly positive effect on mussel density, explaining over $60 \%$ of the distribution of mussels in the area $\left(\mathrm{r}^{2}=0.61, \mathrm{n}=360, \mathrm{p}<0.0001\right.$ square root transformed data). Mean density of mussels decreased from an average of $41975 \pm 8304 \mathrm{~m}^{-2}$ at the most exposed locality to $448 \pm 127 \mathrm{~m}^{-2}$ at the most sheltered location. Due to an extreme depth effect (see below) the relationship was considerably stronger using only mean values per location $\left(\mathrm{r}^{2}=0.86, \mathrm{n}=30, \mathrm{p}<0.0001\right)$. Using the wave model by Isaeus (2004) the corresponding value was $\mathrm{r}^{2}=0.83, \mathrm{n}=30, \mathrm{p}<0.0001$. Pear-

Table 1. Water characteristics in the study area. Samples per location $=14$, sampling locations $=15$. ANOVA was used to relate water characteristics to locations (Baardseth index varied from 0 to 22 at the water sampling sites). TPM: total particulate matter; PIM: particulate inorganic matter; POM: particulate organic matter; ns: not significant

\begin{tabular}{|lrcc|}
\hline Variable & Mean $\pm \mathrm{SD}$ & F-ratio & $\mathrm{p}$ \\
\hline Temperature $\left({ }^{\circ} \mathrm{C}\right)$ & $14.3 \pm 4.2$ & 0.09 & $\mathrm{~ns}$ \\
Oxygen $\left.(\mathrm{mg} \mathrm{l})^{-1}\right)$ & $9.7 \pm 1.1$ & 0.14 & $\mathrm{~ns}$ \\
Salinity $(\mathrm{PSU})$ & $5.9 \pm 0.2$ & 0.07 & $\mathrm{~ns}$ \\
Secchi $(\mathrm{m})$ & $5.6 \pm 1.9$ & 1.11 & $\mathrm{~ns}$ \\
TPM $\left(\mathrm{mg} \mathrm{l}^{-1}\right)$ & $2.4 \pm 1.2$ & 0.27 & $\mathrm{~ns}$ \\
PIM $\left(\mathrm{mg} \mathrm{l}^{-1}\right)$ & $1.4 \pm 0.8$ & 0.40 & $\mathrm{~ns}$ \\
POM $\left(\mathrm{mg} \mathrm{l}^{-1}\right)$ & $1.0 \pm 0.5$ & 0.48 & $\mathrm{~ns}$ \\
Chl a $\left(\mathrm{mg} \mathrm{m}^{-3}\right)^{a}$ & $4.9 \pm 4.2$ & 0.20 & $\mathrm{~ns}$ \\
${ }^{\text {aD } D a t a ~} \log +1$ transformed to meet assumptions of normality \\
\hline
\end{tabular}


son's correlation between the indexes was 0.95 ( $\mathrm{n}=30, \mathrm{p}<0.001)$. The largest deviation was found at the most exposed localities where the index of Isaeus (2004) gave largely similar values for the 6 most exposed localities, whereas the values differed comparatively more using the Baardseth index. Conversely, sheltered sites received more heterogeneous exposure values using the Isaeus fetch-index. The Baardseth index has commonly been used in studies relating wave impact and Fucus ecology (e.g. Ruuskanen et al. 1999) in this area; since neither the significance (p) nor the coefficient of determination $\left(\mathrm{r}^{2}\right)$ differed markedly between the 2 cartographic methods, we hereafter use the Baardseth index only.

The relationship between exposure and density of mussels increased with increasing depth (Fig. 2) being extremely strong at 12 and $8 \mathrm{~m}\left(\mathrm{r}^{2}=0.88\right.$, $\mathrm{n}=90, \mathrm{p}<0.0001$ for both depths), moderate at $5 \mathrm{~m}\left(\mathrm{r}^{2}=0.52, \mathrm{n}=90, \mathrm{p}<0.0001\right)$, and low at $3 \mathrm{~m}\left(\mathrm{r}^{2}=0.28, \mathrm{n}=90, \mathrm{p}<0.0001\right)$. The relative abundance (ratio of total abundance at depth/total abundance at location) of mussels, however, showed a different pattern with declining proportions of mussels at 3 and $5 \mathrm{~m}$ as exposure increased (Fig. 3). At 8 and $12 \mathrm{~m}$, the relative proportion of mussels increased with

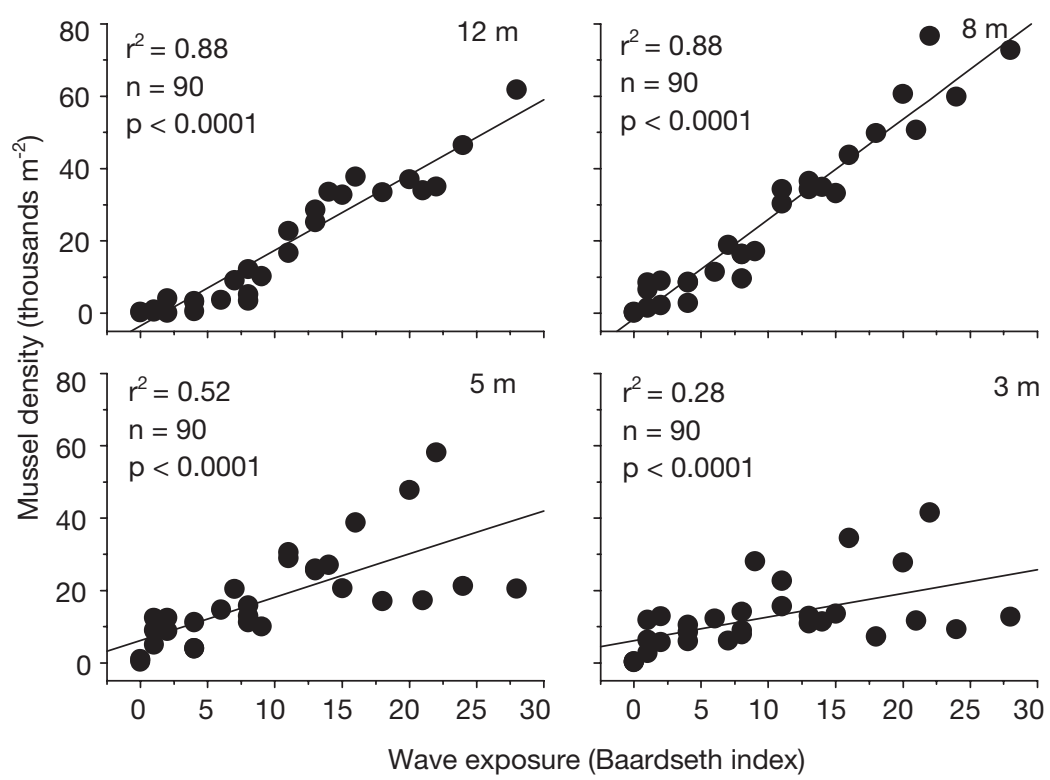

Fig. 2. Mytilus edulis. Relationship between mean density (thousands $\mathrm{m}^{-2}$ ), depth and wave exposure (Baardseth index). For clarity, only mean numbers per location are shown. Statistics are based on the entire data set; data square root transformed to meet assumptions of normality and homoscedasticity increasing exposure. At sheltered locations, most mussels are therefore found in the shallows. On exposed shores, the opposite is seen, with the majority of mussels being found deeper down.

The size structure of mussels also differed with exposure and depth. Maximum size of mussels decreased with increasing exposure (Fig. 4). At all depths, the largest mussels were found at Baardseth index 2 to 4 and decreased towards higher and lower exposure. At all depths, sheltered areas supported bigger mussels (Fig. 4). At the most sheltered locations (Baardseth indexes between 0 and 2), the biggest mussels were found at the shallowest sampling depths whereas at all other localities larger mussels were found on greater depths (Fig. 4). Median size of mussels decreased linearly $\left(\mathrm{r}^{2}=0.57, \mathrm{n}\right.$ $=30, \mathrm{p}<0.0001$ ) with exposure from 7 $\mathrm{mm}$ at the most sheltered sites to $4 \mathrm{~mm}$ at the most exposed sites.

\section{Exposure effects on biomass}

Biomass peaked at intermediate exposure regimes and decreased towards both higher and lower exposure (Fig. 5). Wave exposure had a strong effect on 
biomass but the predictability between wave exposure and mussel biomass was only moderate and levelled off towards the surface to be insignificant at the shallowest sampling depth.

\section{Exposure effects on growth}

There was a marginally inverse relationship between increasing exposure and mean mussel growth per cage, but the predictability was extremely low $\left(\mathrm{r}^{2}\right.$
$=0.03, \mathrm{n}=136, \mathrm{p}=0.04)$. Since competition may influence the outcome of the experiment, only cages with more than 10 surviving mussels at retrieval were accepted for statistical testing. We treated each cage as 1 observation. During the 3 mo experiment, mussels grew on average $0.8 \mathrm{~mm} \pm 0.04$ with maximum growth of individual mussels exceeding $4 \mathrm{~mm}$. Mortality of mussels was higher at offshore than at sheltered localities, but exposure only marginally explained the difference $\left(\mathrm{r}^{2}=0.03, \mathrm{n}=150, \mathrm{p}=0.03\right)$. On average $14 \pm 0.2$ mussels per cage survived throughout the study.

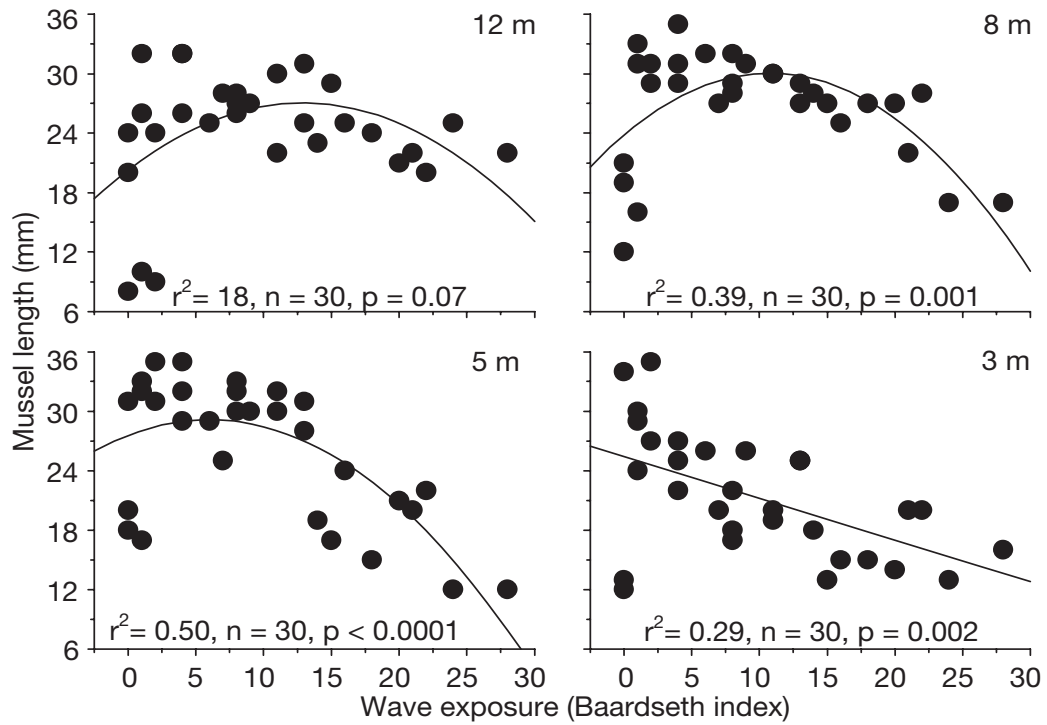

Fig. 4. Mytilus edulis. Maximum size of mussels at different depths and exposure. Each value represents the biggest mussel found at each depth at each locality

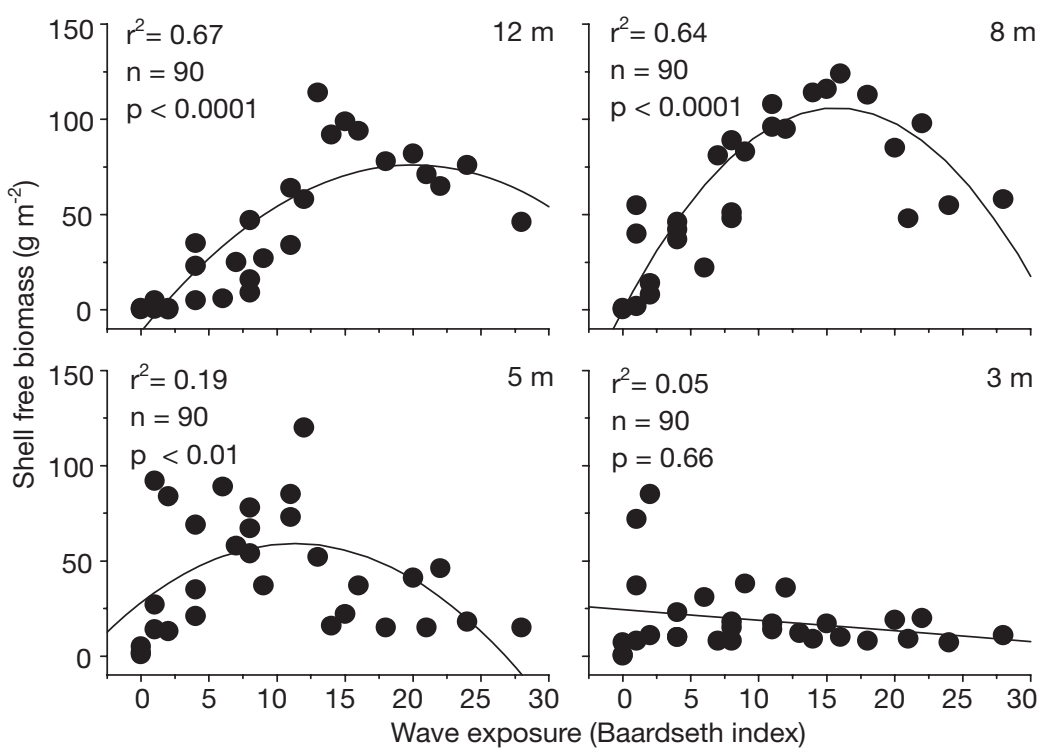

Fig. 5. Mytilus edulis. Relationship between mean shell free biomass $\left(\mathrm{g} \mathrm{m}^{-2)}\right.$, depth and wave exposure. For clarity, only mean numbers per location are shown. Statistics are based on the entire data set; data square root transformed to meet assumptions of normality and homoscedasticity

\section{Recruitment potential in different exposure regimes}

In 2004, mussel recruitment to artificial collectors was influenced by location (Kruskal Wallis $H=127.6$, p < $0.0001)$ but was not explained by exposure (Fig. 6) $\left(\mathrm{r}^{2}=0.002, \mathrm{n}=150, \mathrm{p}=\right.$ $0.26)$. In 2003, however, recruitment to the collectors was higher nearshore than offshore, but the inverse relationship was only marginally explained by exposure (Fig. 6) $\left(\mathrm{r}^{2}=0.09, \mathrm{n}=150, \mathrm{p}<\right.$ 0.001). The number of mussels was extremely high in 2004 (1034 \pm 41 mussels $\mathrm{dm}^{-1}$ rope, corresponding to over $250000 \mathrm{~m}^{-2}$ ) and comparatively low in $2003\left(119 \pm 7 \mathrm{dm}^{-1}\right.$ rope, corresponding to $30000 \mathrm{~m}^{-2}$ ). The size of the recruits ranged from 0.4 to $1.1 \mathrm{~mm}$ with a modal size of approx. $0.6 \mathrm{~mm}$. Sporadic plankton sampling recorded high numbers of pelagic lamellibranchiate larvae in early to mid July 2003.

\section{DISCUSSION}

\section{Response of adult mussels to varying exposure}

The significance of wave action on abundance and size structure of mussels is clearly shown in this study. The results support the findings of previous work, that wave exposure is a highly important factor in the distribution and size structure of mussels on rocky shores. Here, densities of mussels increased progressively with increasing exposure. This increase could originate from increasing 


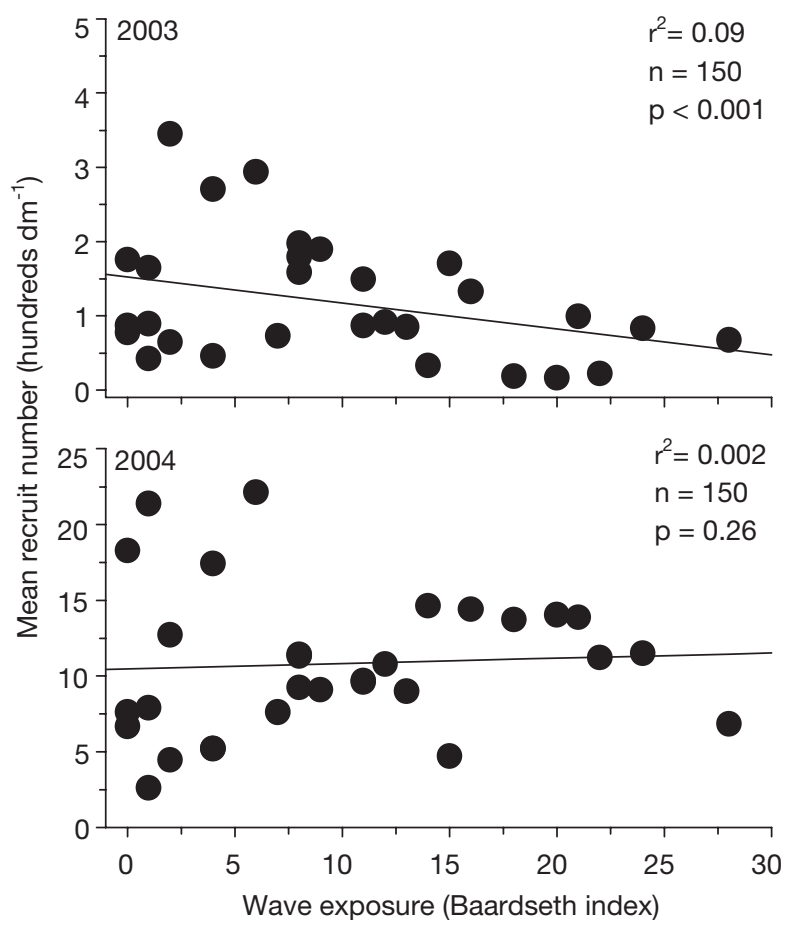

Fig. 6. Mytilus edulis. Recruitment in relation to exposure (at $8 \mathrm{~m}$ depth) during 2003 and 2004. Statistics are based on the entire data set; only means are shown

feeding resources along the exposure gradient (Gardner 2000, McQuaid \& Lindsay 2000, Morgan 2001). Higher water flow and particle delivery increase the carrying capacity of the shore, and habitats with high water flow generally maintain higher densities of suspension feeders. However, in this study, no real difference along the exposure gradient was seen in feeding conditions, and both the quality (chl $a$, POM) and quantity (chl $a$, TPM) of available food remained similar between localities with different exposure. Therefore, lack of feeding resources landwards seems not to be the ultimate reason for the observed pattern of declining numbers of mussels towards sheltered localities. However, greater water flow increases particle availability and keeps particles in suspension for a longer time, thereby increasing feeding time and feeding efficiency (Fréchette et al. 1989). Therefore, low water circulation with subsequent reductions in food delivery can potentially contribute to the observed pattern of mussel distribution in this area.

The growth of mussels in the caging experiment indicated a slow growth rate among blue mussels (see also Westerbom et al. 2002). Vuorinen et al. (2002) and Steffani \& Branch (2003) suggested slower growth rates of mussels at offshore areas relative to more sheltered areas. In the present study, however, the ecological significance of the marginally higher growth rate landward relative to seaward localities is somewhat obscure, as the difference in recorded food concentrations was non-significant and water-flow probably is slower landward than seaward. Higher concentrations of mussels at offshore localities will increase intraspecific competition for possibly limited food resources reducing the relative availability of feeding particles per mussel. This effect may not have been revealed by the water samples. Increased competition may also explain the trend of a marginally lower growth rate and a marginally higher mortality rate of mussels at offshore sites and may partially explain the smaller median size of mussels in offshore areas. Steffani \& Branch (2003) discussed several reasons for slower growth in offshore areas relative to sheltered ones, including higher costs of byssus production, thicker shells and, under extreme wave conditions, inhibitions of the filtration capacity. These factors are probably also of importance in the area of the present study and may have contributed to the observed pattern.

Biomass of mussels reached peak values at moderately exposed areas indicating optimal conditions for individual mussels at intermediate exposure. This was especially evident at 12 and $8 \mathrm{~m}$, whereas the polynomial relationship was less clear at $5 \mathrm{~m}$ and became linear at $3 \mathrm{~m}$ where detrimental effects of wave exposure probably influenced the pattern. Dislodgement of large individuals, in concert with higher energetic demands, may explain the decline in biomass from extreme exposure to moderate exposure, whereas the comparatively low abundance of mussels at sheltered areas explains the decline from intermediate to sheltered areas (also median size of mussels increased towards sheltered areas). Similar polynomial relationships between biomass of rocky shore mussels and wave exposure have been documented elsewhere (Hammond \& Griffiths 2004), and the condition of mussels has been shown to peak in areas of intermediate exposure (Steffani \& Branch 2003, Branch \& Steffani 2004).

\section{Recruitment and predation as explanations for the gradient}

In this study, exposure did not influence the number of potential recruits, indicating that it is neither a lack of pelagic larvae nor a lack of settlers that determines the low density of mussels at wave protected localities. Problems in recruitment processes to adult populations (from the pelagic phase to the rocky bottom) and/or early post-recruitment mortality, however, may limit mussel density at wave-protected sites.

In the study area, the occurrence of perennial red algae is higher at offshore than at sheltered localities (Kiirikki 1996) and, since filamentous algae are highly preferred by mussel larvae (Seed \& Suchanek 1992, 
Erlandsson \& McQuaid 2004), it is possible that larvae settle proportionately more on artificial substrates landwards than seawards because of a shortage of algae landwards. Nevertheless, during both years of study, settlement on artificial collectors was high, indicating that the supply of settlers would probably be more than sufficient to maintain adult densities also at sheltered localities. Therefore, lack of pelagic larvae is unlikely to be the limiting factor resulting in low densities of landward mussels. Furthermore, spat collectors were submerged at $8 \mathrm{~m}$ depth (to avoid movements by waves) while the highest number of settlers and recruits have been recorded at much shallower depths (Littorin \& Gilek 1999a, Vuorinen et al. 2002), indicating that there are even more potential settlers than our results suggest. Long-term monitoring data on exposed and sheltered shores (including shores in this study) show large spatial and temporal differences in the density of recruits and small mussels (2 to $3 \mathrm{~mm}$ ), but the localities maintain their relative rankings, suggesting that the results in this study are persistent (M. Westerbom, O. Mustonen, M. Kilpi \& J. T. Lehtonen unpubl.).

Wave exposed shores create refuges from predation resulting in higher abundances of prey in physically harsh environments (Menge \& Branch 2001 and references therein, Siddon \& Witman 2003). Hydrodynamic forces generated by waves generally reduce predation pressure by reducing foraging efficiency or foraging time of mobile predators and increasing predator mortality (Siddon \& Witman 2003). However, studies carried out in the northern Baltic suggest that predation pressure on blue mussels is negligible due to a lack of major invertebrate predators on mussels (Reimer \& Harms-Ringdahl 2001 and references therein). Vertebrate predators (various cyprinid fish and sea ducks) in our study area account for a strong predation pressure (Öst \& Kilpi 1997, Westerbom et al. 2002, Lappalainen et al. 2005). These predators mostly concentrate on the upper end of the size distribution of mussels and may not contribute to the low occurrence of recently (1 to 2 yr) colonised mussels in more sheltered localities that are far too small ( 2 to $6 \mathrm{~mm}$ ) to be actively selected by these predators (Öst \& Kilpi 1998, Lappalainen et al. 2005). Young sea ducks probably consume smaller mussels than those eaten by adults for a short time only, and small cyprinids have been shown to concentrate on food items other than mussels (e.g. Prejs et al. 1990). Although predation seems to be an unlikely reason for the overall decline in mussel abundances along the gradient, it may well have influenced mussel populations at some locations. Where mussel abundances are initially low, predation may primarily influence both numbers and size structure of mussels with secondary effects on recruiting juveniles.

\section{Sedimentation and mussel colonisation}

It is apparent that substantial numbers of young mussels disappear from the populations between settlement (as recorded in the recruitment experiment) and the point at which surviving mussels reach the size of 2 to $3 \mathrm{~mm}$ (and are captured by the smallest mesh in our study). It is further apparent that this decline in numbers is considerably stronger landwards than seawards and that the factor causing this thinning of populations gradually increases towards progressively more sheltered sites.

Sediment deposition is an important physical process in coastal environments having a profound ecological effect on rocky shore organisms (Eriksson \& Bergström 2005). Hydrodynamic conditions and sediment load are closely associated since low water movement enables sediments to accumulate on rocky bottoms while high water flow keeps bottoms free of sediments (Kiirikki 1996). Therefore, it is difficult to separate the effects of wave exposure and the effects of sediment load. In this archipelago, sediment covered bottoms are governed by wave action, increasing towards sheltered areas and greater depths (Kiirikki 1996). Even low amounts of sediments may prevent bivalve settlement (e.g. Hunt \& Scheibling 1997), and siltation may explain the absence of rocky shore mussels in subtidal areas (Branch \& Steffani 2004). Sedimentation may also indirectly affect settlement by preventing establishment of perennial algal stands (Santos 1993, Kiirikki 1996, Eriksson \& Bergström 2005). In the northern Baltic, the effects of siltation on mussel recruitment may be pronounced, as the bedrock is generally very smooth. Hence, in the absence of resident adult conspecifics and thinned populations of perennial algae or other protruding structures, in combination with thin films of sediments on the sublittoral rocks, small mussels may meet considerable problems in gaining a permanent foothold and may be permanently lost when these sediments are eventually redistributed. Sediments have further been shown to impair feeding efficiency among suspension feeding bivalves by damaging the filtering apparatus and disrupting active filtering, thereby reducing the intake of food (Cheung \& Shin 2005). It is evident that where sediments (especially inorganic) accumulate on rocky bottoms, this problem will be more severe among those individuals that have their inhalant siphons close to the bottom. It is therefore likely that small mussels living close to the bottom (and not on larger conspecifics or algae), as they have to do in sheltered areas where both adults and perennial algae are few, are more susceptible to this detrimental sedimentation effect.

Re-colonisation of empty space by Baltic blue mussels may thus be an extremely slow process relying 
more on redistribution of established mussels than recolonisation by recruits, despite the presence of high larval numbers (Littorin \& Gilek 1999b). In environments where the availability of adult mussels is initially low, and hence less redistribution occurs, reestablishment of mussels will evidently be slow.

\section{Vertical distribution of mussels along the exposure gradient}

Physical disturbance from wave action peaks at the fringe between land and sea and decreases with depth as wave energy decreases (Witman \& Dayton 2001, Siddon \& Witman 2003). Dislodgement by wave forces is expected to increase isometrically with increasing size of mussels and increasing exposure, leading to smaller mussels on exposed shores (Alvarado \& Castilla 1996) and shallow depths. Larger mussels can therefore only live at greater depths at the most exposed localities. These predictions are supported by the findings in this study, where we generally found larger mussels on sheltered shores. At exposed localities, larger mussels were found at greater depths but were absent at the 2 shallowest depths. Negative effects of exposure were however also observed in the sheltered localities, but here the pattern was reversed with generally larger mussels at shallower depths. The reasons for this reversed pattern in sheltered areas may be (1) negative sedimentation effects, (2) food limitation or (3) predation effects. If predation is relatively more important landwards than seawards, it should also be observed at the shallower depths, since landward wave action should not prevent predation here. Landwards, mussels were abundant at the 2 shallower depths but decreased markedly towards deeper bottoms, and this decrease was related to wave exposure (Fig. 3), indicating that predation can hardly explain the observed pattern. The effects of sedimentation or reduced feeding conditions are difficult to separate since reduced water flow affects both food availability (by decreasing rate of supply) and sedimentation on bottoms. Sedimentation accounts for the depth distribution of suspension feeding invertebrates in some marine areas (Witman \& Dayton 2001). We believe that combinations of reduced feeding opportunities and loose thin films of sediments on rocky surfaces are partly responsible for the vertical distribution found in this study area, causing recruitment problems or high post-recruitment mortality of mussels at progressively more sheltered sites. We suggest that declining numbers of mussels at progressively more sheltered sites are controlled by combined effects of reduced feeding conditions (rate of food supply) and periodic sedimentation effects (both primary and secondary) affecting colonisation success of recruits to adult populations and increasing post-recruitment mortality. We also believe that proximate predator effects on mainly adult abundance back up these ultimate factors by thinning out adult populations.

Acknowledgements. We thank Dr M. Kilpi and 4 anonymous referees for constructive and valuable comments on an earlier version of the manuscript. O. Mustonen is acknowledged for help in the field. We thank G. Sundblad for computing the fetch indexes. The study was supported by the EU-project Mål 2 (AC 340165) and grants from Svenska kulturfonden, Oscar Öflunds stiftelse, Waldemar von Frenckells stiftelse, Walter och Andrée de Nottbecks stiftelse and Onni Talaan säätiö. The work complies with current laws in Finland.

\section{LITERATURE CITED}

Alvarado JL, Castilla JC (1996) Tridimensional matrices of mussels Perumytilus purpuratus on intertidal platforms with varying wave forces in central Chile. Mar Ecol Prog Ser 133:135-141

Baardseth E (1970) A square-scanning,two stage sampling method of estimating seaweed quantities. Rep Norw Inst Seaweed Res 33:1-41

Branch GM, Steffani CN (2004) Can we predict the effects of alien species? A case-history of the invasion of South Africa by Mytilus galloprovincialis (Lamarck). J Exp Mar Biol Ecol 300:189-215

Bustamante RH, Branch GM (1996) Large scale patterns of trophic structure of southern African rocky shores: the roles of geographic variation and wave exposure. J Biogeogr 23:339-351

Bustamante RH, Branch GM, Eekhout S, Robertson B and 7 others (1995) Gradients of intertidal productivity around the coast of South Africa and their relationships with consumer biomass. Oecologia 102:189-201

Cheung SG, Shin PKS (2005) Size effects of suspended particles on gill damage in green-lipped mussel Perna viridis. Mar Pollut Bull 51:801-810

Dahlhoff EP, Menge BA (1996) Influence of phytoplankton concentration and wave exposure on the ecophysiology of Mytilus californianus. Mar Ecol Prog Ser 144:97-107

Denny M (1995) Predicting physical disturbance: mechanistic approaches to the study of survivorship on wave-swept shores. Ecol Monogr 65(4):371-418

Eriksson BK, Bergström L (2005) Local distribution patterns of macroalgae in relation to environmental variables in the northern Baltric Proper. Estuar Coast Shelf Sci 62:109-117

Erlandsson J, McQuaid CD (2004) Spatial structure of recruitment in the mussel Perna perna at local scales: effects of adults, algae and recruit size. Mar Ecol Prog Ser 267: 173-185

Fréchette M, Butman CA, Geyer WR (1989) The importance of boundary layer flows in supplying phytoplankton to the benthic suspension feeder, Mytilus edulis, L. Limnol Oceanogr 34:19-36

Gardner JPA (2000) Where are the mussels on Cook Strait (New Zealand) shores? Low seston quality as a possible factor limiting multi-species distributions. Mar Ecol Prog Ser 194:123-132

Hammond W, Griffiths CL (2004) Influence of wave exposure on South African mussel beds and their associated infaunal communities. Mar Biol 144:547-552 
Hunt HL, Scheibling RE (1996) Physical and biological factors influencing mussel (Mytilus trossulus, M. edulis) settlement on a wave-exposed rocky shore. Mar Ecol Prog Ser 142:135-145

Hunt HL, Scheibling RE (1997) Role of early post-settlement mortality in recruitment of benthic marine invertebrates. Mar Ecol Prog Ser 155:269-301

Hunt HL, Scheibling RE (2001) Patch dynamics of mussels on rocky shores: integrating process to understand pattern. Ecology 82(11):3213-3231

Isaeus M (2004) Factors structuring Fucus communities at open and complex coastlines in the Baltic Sea. PhD dissertation, Stockholm University

Kiirikki M (1996) Mechanisms affecting macroalgal zonation in the northern Baltic Sea. Eur J Phycol 31:225-232

Lappalainen A, Westerbom M, Heikinheimo O (2005) Roach (Rutilus rutilus) as important predators on blue mussel (Mytilus edulis) populations in a brackish-water environment, the northern Baltic Sea. Mar Biol 147:323-330

Lawrie SM, McQuaid CD (2001) Scales of mussel bed complexity: structure, associated biota and recruitment. J Exp Mar Biol Ecol 257:135-161

Littorin B, Gilek M (1999a) Vertical patterns in biomass, size structure, growth and recruitment of Mytilus edulis in an archipelago area in the northern Baltic Sea proper. Ophelia 50:93-112

Littorin B, Gilek M (1999b) A photographic study of the recolonization of cleared patches in a dense population of Mytilus edulis in the northern Baltic proper. Hydrobiologia 393:211-219

Martel A, Mathieu AF, Findlay CS, Nepszy SJ, Leach H (1994) Daily settlement rates of the Zebra mussel, Dreissena polymorpha, on an artificial substrate correlate with veliger abundance. Can J Fish Aquat Sci 51:856-861

McQuaid CD, Branch GM (1985) Trophic structure of rocky intertidal communities: response to wave action and implications for energy flow. Mar Ecol Prog Ser 22:153-161

McQuaid CD, Lindsay TL (2000) Effect of wave exposure on growth and mortality rates of the mussel Perna perna: bottom-up regulation of intertidal populations. Mar Ecol Prog Ser 206:147-154

McQuaid CD, Lindsay JR, Lindsay TL (2000) Interactive effects of wave exposure and tidal height on population structure of the mussel Perna perna. Mar Biol 137:925-932

Menge BA, Branch GM (2001) Rocky intertidal communities. In: Bertness MD, Gaines SD, Hay ME (eds) Marine community ecology. Sinauer Associates, Sunderland, MA, p 221-251

Morgan SG (2001) The larval ecology of marine communities. In: Bertness MD, Gaines SD, Hay ME (eds) Marine community ecology. Sinauer Associates, Sunderland, MA, p 159-181

Öst M, Kilpi M (1997) A recent change in size distribution of blue mussels (Mytilus edulis) in the western part of the Gulf of Finland. Ann Zool Fenn 34:31-36

Öst M, Kilpi M (1998) Blue mussels Mytilus edulis in the Baltic: good news for foraging eiders Somateria mollis-

Editorial responsibility: Howard I. Browman (Associate Editor-in-Chief), Storebø, Norway sima. Wildl Biol 4:81-89

Pearson GA, Brawley SH (1996) Reproductive ecology of Fucus distichus (Phaeophyceae): an intertidal alga with successful external fertilization. Mar Ecol Prog Ser 143: $211-223$

Prejs A, Lewandowski K, Stanczykowska-Piotrowska A (1990) Size-selective predation by roach (Rutilus rutilus) on zebra mussel (Dreissena polymorpha): field studies. Oecologia 83:378-384

Reimer O, Harms-Ringdahl S (2001) Predator-inducible changes in blue mussels from the predator-free Baltic Sea. Mar Biol 139:959-965

Robles CD, Alvarado MA, Desharnais RA (2001) The shifting balance of littoral predator-prey interaction in regimes of hydrodynamic stress. Oecologia 128:142-152

Rule JM, Smith SDA (2005) Spatial variation in the recruitment of benthic assemblages to artificial substrata. Mar Ecol Prog Ser 290:67-78

Ruuskanen A, Bäck S, Reitalu T (1999) A comparison of two cartographic exposure methods using Fucus vesiculosus as an indicator. Mar Biol 134:139-145

Ruuskanen AT, Nappu NP (2005) Morphological differences in Fucus gardneri between two shores with equal cartographic exposure values but different levels of wave action. Ann Bot Fenn 42:27-33

Santos R (1993) A multivariate study of biotic and abiotic relationships in a subtidal algal stand. Mar Ecol Prog Ser 94: 181-190

Seed R, Suchanek TH (1992) Population and community ecology of Mytilus. In: Gosling EM (ed) The mussel Mytilus: ecology, physiology, genetics and culture. Elsevier, Amsterdam, p 87-169

Siddon CE, Witman JD (2003) Influence on chronic, low-level hydrodynamic forces on subtidal community structure. Mar Ecol Prog Ser 261:99-110

Steffani CN, Branch GM (2003) Growth rate, condition, and shell shape of Mytilus galloprovincialis: responses to wave exposure. Mar Ecol Prog Ser 246:197-209

Stewart HL, Carpenter RC (2003) The effects of morphology and water flow on photosynthesis of marine macroalgae. Ecology 84(11):2999-3012

Viitasalo M, Vuorinen I, Saesmaa S (1995) Mesozooplankton dynamics in the northern Baltic Sea: implications of variation in hydrography and climate. J Plankton Res 17: 1857-1878

Vuorinen I, Antsulevich AE, Maximovich NV (2002) Spatial distribution and growth of the common mussel Mytilus edulis $\mathrm{L}$ in the archipelago of SW-Finland, northern Baltic Sea. Boreal Environ Res 7:41-52

Westerbom M, Kilpi M, Mustonen O (2002) Blue mussels, Mytilus edulis, at the edge of the range: population structure, growth and biomass along a salinity gradient in the northeastern Baltic Sea. Mar Biol 140:991-999

Witman JD, Dayton PK (2001) Rocky subtidal communities. In: Bertness MD, Gaines SD, Hay ME (eds) Marine community ecology. Sinauer Associates, Sunderland, MA, p 339-367

Submitted: May 3, 2005; Accepted: September 9, 2005 Proofs received from author(s): November 24, 2005 